\title{
Clinical trial for evaluation of Ricinus communis and sodium hypochlorite as \\ denture cleanser
}

\section{Abstract}

Maurício Malheiros BADARÓ1

Marcela Moreira SALLES ${ }^{1}$

Vanessa Maria Fagundes LEITE ${ }^{1}$

Carolina Noronha Ferraz de ARRUDA ${ }^{1}$

Viviane de Cássia OLIVEIRA ${ }^{1}$

Cássio do NASCIMENTO'

Raphael Freitas de SOUZA ${ }^{1}$

Helena de Freitas de

Oliveira PARANHOS ${ }^{1}$

Cláudia Helena SILVA-LOVATO' ${ }^{1}$
Submitted: May 02, 2016 Modification: November 04, 2016 Accepted: November 27, 2016
The development of opportunistic infections due to poor denture hygiene conditions justified the search for effective hygiene protocols for controlling denture biofilm. Objective: This study evaluated Ricinus communis and sodium hypochlorite solutions in terms of biofilm removal ability, remission of candidiasis, antimicrobial activity, and participant satisfaction. Material and Methods: It was conducted a controlled clinical trial, randomized, doubleblind, and crossover. Sixty-four denture wearers with $(n=24)$ and without candidiasis $(n=40)$ were instructed to brush ( 3 times/day) and immerse their dentures (20 min/day) in different storage solutions (S1 / S2: 0.25\% / $0.5 \%$ sodium hypochlorite; S3: 10\% R. communis; S4: Saline).The trial period for each solution was seven days and a washout period of seven days was used before starting the use of another solution. The variables were analyzed at baseline and after each trial period. The biofilm of inner surfaces of maxillary dentures was disclosed, photographed, and total and dyed areas were measured (Image Tool software). The percentage of biofilm was calculated. Remission of candidiasis was assessed by visual scale and score were attributed. Antimicrobial activity was assessed by the DNACheckerboard hybridization method. Patient satisfaction was measured using

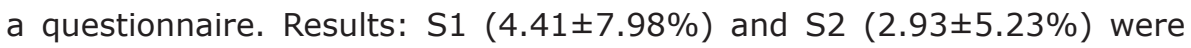
more effective then $\mathrm{S} 3(6.95 \pm 10.93 \%)$ in biofilm remotion $(P<0.0001)$. All solutions were different from the control $(11.07 \pm 11.99 \%)$. S3 was the most effective solution in remission of candidiasis (50\%), followed by S1 (46\%). Concerning antimicrobial action, S1/S2 were similar and resulted in the lowest microorganism mean count $(P=0.04)$, followed by $S 3$. No significant differences were found with patient's satisfaction. Conclusions: $10 \% \mathrm{R}$. communis and $0.25 \%$ sodium hypochlorite were effective in biofilm removal, causing remission of candidiasis and reducing the formation of microbial colonies in denture surfaces. All solutions were approved by patients.

Keywords: Denture. Biofilms. Candidiasis. Disinfection.
Corresponding address: Prof. Dra ${ }^{\text {a }}$. Cláudia Helena Lovato da Silva Departamento de Materiais Dentários e Prótese - Faculdade de Odontologia de Ribeirão Preto Universidade de São Paulo - Avenida do Café $s / n$. 14040-904 - Ribeirão Preto - SP - Brazil. Phone: $+55(16) 3315-4006$ e-mail: chl@forp.usp.br
'Universidade de São Paulo, Faculdade de Odontologia de Ribeirão Preto, Departamento de Materiais Dentários e Prótese, Ribeirão Preto, SP, Brazil 


\section{Introduction}

Complete denture is a potential microbial reservoir, which can lead to infections and inflammatory diseases. Several studies have examined the development of microbial colonies in dentures and in the supporting soft and hard oral tissues $22,24,25,28$. Species commonly found in the oral microbiota of healthy individuals can cause chronic atrophic candidiasis and systemic diseases such as bacterial endocarditis, intestinal infection, chronic obstructive pulmonary disease and aspiration pneumonia2,21.

Correct denture hygiene is essential to reduce or eliminate pathogens ${ }^{15,22,23}$ and establish an environment suitable for the growth of beneficial oral microbiota. Studies have shown that a combination of mechanical and chemical cleaning is efficient in the maintenance of denture hygiene ${ }^{7,22}$.

Among chemical solutions, sodium hypochlorite ( $1 \%$ and $0.5 \% \mathrm{NaClO}$ ) is the most commonly used and shows good bactericidal and fungicidal properties ${ }^{15,22,23}$. However, these solutions may adversely affect physical and mechanical properties of the denture ${ }^{4,17}$. In addition, the unpleasant taste and odor of $\mathrm{NaClO}$ may cause some discomfort for patients, although there aren't studies that have evaluated the extent of this problem. These aspects may influence the acceptance of antiseptic solutions by denture wearers and, therefore, their usage on a regular basis could be lower than shown in short-term trials ${ }^{29}$. Therefore, studies using lower concentrations are needed.

The method chosen for home prosthetic care should be effective in removing organic and inorganic debris, exhibit fungicidal and bactericidal properties, be compatible with the structural material of the prosthesis, be non-toxic to users, have low cost, and be easy to handle. Since most of the current methods used for denture hygiene do not present all these characteristics, numerous studies have been conducted in an attempt to find an optimal protocol $2,4,7,10,16,19,20,22-24,26,27,29$.

The R. communis solution has been studied as a potential denture cleaner, since it acts as a detergent and has antimicrobial properties. Moreover, it does not have toxic effects on oral tissues ${ }^{2,9,18-20}$. R. communis derives from the castor plant (Ricinus communis; division Magnoliophyta, class Magnoliopside, subclass Rosidae, order Euforbiales, family Euforbiaceae), which is a vegetable native to the Middle East and the northeastern Africa, but is commonly found in tropical climate areas such as Brazil11,20. The presence of a hydroxyl group, a single point of unsaturation and a carboxyl group - three highly reactive functional groups in the ricinoleic acid present in the castor oil composition - give R. communis important oilchemical potential. It may be subjected to various chemical processes to obtain by-products used in the pharmaceutical and cosmetic industry, in the production of lubricants, polymers, biodiese ${ }^{11,12}$, and more specifically in medical and dental products. Although a few studies have focused on the use of R. communis in complete dentures, the available results are promising 2,4,19,20,22,23, particularly at a concentration of $10 \% 10,22,23$. However, although controlled clinical trials assess this oil's ability to remove biofilm, its antimicrobial properties and patient acceptability are inconclusive, and call for further investigation.

Thus, the aim of this clinical study was to evaluate the effectiveness of $10 \%$ Ricinus communis and $0.25 \% \mathrm{NaClO}$ solution as denture cleaning agents. The properties assessed include the ability to remove biofilm, to reduce candidiasis, as well as antimicrobial properties and patient satisfaction. Results were compared with $0.5 \%$ sodium hypochlorite and saline. The first null hypothesis was that $10 \% \mathrm{R}$. communis, $0.25 \%$ sodium hypochlorite and $0.5 \%$ sodium hypochlorite denture cleansers would have the same ability to remove biofilm, to cause remission of candidiasis, as well as the same antimicrobial action. The second null hypothesis was that immersion in $10 \%$ R. communis would have the same acceptance as saline by the patients.

\section{Methodology}

This protocol was approved by the institutional Ethics Committee (CAAE-0013.0.138.000-07) and registered at ClinicalTrials.gov (NC T02407834; U.S. National Institutes of Health). Regular patients from Ribeirão Preto Dental School were invited to participate. Inclusion criteria were: having good general health and motor coordination; wearing conventional maxillary dentures fabricated with heatactivated acrylic resin and in use for 5 to 10 years; and presenting biofilm in the inner surface of dentures (Additive index ${ }^{1}$ ). Exclusion criteria were: systemic diseases known to foster the growth of Candida 
(e.g., uncontrolled diabetes; immunosuppressive disorders; anemia; xerostomia); use of antibiotics, antifungal agents or corticosteroids; having received chemotherapy or radiotherapy in the last four weeks prior to enrollment in the study. Evidences for denture adaptation problems, the need for reline, repair, or a fractured denture also led to the exclusion of the participant.

Variables of quantitative response were effectiveness of biofilm removal, remission of candidiasis and antimicrobial action. As a qualitative variable, the acceptance of the solutions by the participants was analyzed. Participants were instructed to brush their dentures three times a day (after breakfast, lunch, and dinner) with a specific brush (Bitufo ${ }^{\circledR}$, Itupeva, SP, Brazil) and neutral liquid soap (Pleasant, Perol Commercial and Industrial Ltda., Ribeirão Preto, SP, Brazil), and to soak the dentures for $20 \mathrm{~min}$, once a day, in $200 \mathrm{~mL}$ of the following solutions: S1: $0.25 \%$ sodium hypochlorite (Inject Center, Ribeirão Preto, SP, Brazil); S2: $0.5 \%$ sodium hypochlorite (Inject Center); S3: 10\% R. communis oil solution (Institute of Chemistry, University of São Paulo, São Carlos, SP, Brazil); and S4: $0.85 \%$ saline solution (control; sodium chloride P.A.; Labsynth Laboratory Products Ltda., Diadema, SP, Brazil). All participants used each solution for seven days in a random sequence (cross-over). Following each period of use, there was a 1-week washout period during which the patients used the specific brush and neutral liquid soap to clean their dentures, in order to eliminate the residual effect of previous treatment (carry over effect) ${ }^{22}$. Participants were instructed to rinse dentures before insertion into the oral cavity and keeping the dentures immersed in water overnight.

For the blinding of involved parts, the products were distributed in unidentified vials (solutions) and delivered without identification to participants, as follows: Researcher P1 obtained a list of random numbers (Excel 2013, Microsoft Brazil, Sao Paulo, SP, Brazil), corresponding to the possible sequences of treatments. All possible sequences had the same probability of being assigned. Researcher P2 received the random numbers and distributed the products to the participants according to the codes. Researcher P3 provided the hygiene instructions and applied the questionnaire. Researchers P4 and P5 were responsible for the take of the dentures, biofilm staining, and subsequent total biofilm elimination. Researchers P6 and P7 obtained the photographs of the dentures, collected the biofilm, and processed it by DNACheckerboard method. Researcher P8 conducted biofilm quantification, tabulated the variables, and forwarded the data to researcher P9, who performed the statistical analysis.

\section{Biofilm quantification}

Baseline conditions were recorded for all participants. The intaglio surfaces of the upper dentures were dyed ( $1 \%$ neutral red) and photographed (Canon EOS Digital Rebel EF-S 18-55; Canon MR-14 EX flash, Canon Inc., Tokyo, Japan) with the camera fixed on a stand (CS-4 Copy Stand, Testrite Inst. Co., Inc., Newark, NJ, USA), maintaining a standard film-object distance and controlling exposure time. Images were transferred to a computer, and total surface and stained areas were measured (Software ImageTool 3.0, UTHSC, San Antonio, USA). Biofilm percentage was calculated by the biofilm/total surface area ratio of the denture multiplied by $100^{16,26}$. Thereafter, the biofilm on the denture surface was removed by a researcher (P4 and P5) using a brush with neutral liquid soap. All participants received cleaned dentures at the start of the experimental period. After each experimental period, the intaglio surfaces of the dentures were dyed, and the disclosed biofilm was photographed and analyzed, as previously described.

\section{Candidiasis assessment}

The palatal mucosa of the participants with candidiasis was photographed with the camera focused on the mid-palatal raphe region, with adequate visualization of the entire region, which includes the incisive papilla until the right and left tuberosity. Images were obtained at baseline after seven days of each intervention and after washout periods. Images were transferred to a computer and the Prosthodontic Tissue Index ${ }^{5}$ was applied following scores: "0"(excellent): normal tissue, pink surface, with normal vascularization and appearance; "1" (satisfactory): reddish inflamed mucosa with areas of focal hyperemia, but generally normal appearance; " 2 " (poor): reddish mucosa with multiple hyperemic areas and widespread shiny surface; "3" (unsatisfactory): markedly red mucosa with or without focal hyperemia, shiny surface and granular inflammation.

\section{Participant satisfaction}

Participants' satisfaction was measured by the 
following questions: Q1) Does the product used this week cleaned your prosthesis?; Q2) What is your perception about the smell of the product?; Q3) Did the product leave any taste on your denture?; Q4) Was the product easy to use?; Q5) Would you use the product daily?; Q6) Would you recommend this product to a friend? The questions were answered on a 0-10 scale, in which " 0 " was the worst possible (most negative) answer and "10" the best possible (most positive) answer.

\section{Antimicrobial action}

DNA-Checkerboard hybridization method was used to assess antimicrobial effect of the solutions ${ }^{13}$. Biofilm was collected from the inner surface of the dentures (incisive papilla, left and right tuberosity regions, regions with the highest propensity to biofilm accumulation) with a sterile microbrush at baseline and after seven days of each treatment. The active tips of the microbrushes were individually inserted into microtubes containing $150 \mu \mathrm{L}$ of buffer TE $(10 \mathrm{mM}$ Tris- $\mathrm{HCl}, 1$ mM EDTA, $\mathrm{pH}$ 7.6), followed by addition of $150 \mu \mathrm{L}$ of $0.5 \mathrm{M} \mathrm{NaOH}$ to cause cell lysis.

In short, DNA clinical samples were collected, denatured, precipitated, applied in individual lanes, and fixed onto nylon membranes. For standard samples, mixtures of genomic DNA comprising $10^{5}$ or $10^{6}$ microbial cells of each analyzed species were assembled, denatured, precipitated and applied into two control slots. Membranes were pre-hybridized $\left(60^{\circ} \mathrm{C}, 2 \mathrm{~h}\right)$ in a hybridization buffer consisting of $\mathrm{NaCl}$ at $0.5 \mathrm{M}$ and blocking reagent at $0.4 \%$ (w/vol). Thereafter, membranes received specific aliquots of labeled, whole genomic probes of the proposed target species and hybridized overnight at $60^{\circ} \mathrm{C}$ under gentle agitation. On the following day, membranes were washed twice in primary wash buffer $\left(65^{\circ} \mathrm{C}, 30\right.$ min) and twice in a secondary wash buffer (at room temperature for $15 \mathrm{~min}$ ). After washing, hybrids were directly detected by chemiluminescence using the Gene Images CDP-Star Reagent (GE Healthcare, UK). Exposure of the membrane to ECL Hyperfilm-MP (GE Healthcare, UK) for 30 min enabled the detection of hybridization. Images on the hyperfilm were digitized and analyzed with the use of TotalLab Quant analysis software (TotalLab Life Science Analysis Essentials; Newcastle upon Tyne). This software translates pixel intensity into amount of microbial cells by comparing samples with standard reference lanes on the membrane. Forty three target species were analyzed,

\begin{tabular}{|c|c|c|c|}
\hline Species & ATCC & Species & ATCC \\
\hline Candida albicans & 10231 & Porphyromonas endodontalis & 35406 \\
\hline Candida dubliniensis & MYA 646 & Porphyromonas gingivalis & 33277 \\
\hline Candida glabrata & 90030 & Prevotella intermedia & 25611 \\
\hline Candida krusei & 6258 & Prevotella melaninogenica & 25845 \\
\hline Candida tropicalis & 750 & Prevotella nigrescens & 33563 \\
\hline Aggregatibacter actinomycetemcomitans serotype a & 29522 & Pseudomonas aeruginosa & 27853 \\
\hline Aggregatibacter actinomycetemcomitans serotype $b$ & 29523 & Pseudomonas putida & 12633 \\
\hline Bacteroides fragilis & 25285 & Solobacterium moorei & CCUG39336 \\
\hline Campylobacter rectus & 33238 & Staphylococcus aureus & 25923 \\
\hline Capnocytophaga gingivalis & 33624 & Staphylococcus pasteuri & 51129 \\
\hline Eikenella corrodens & 23834 & Streptococcus constellatus & 27823 \\
\hline Enterococcus faecalis & 51299 & Streptococcus gordonii & 10558 \\
\hline Escherichia coli & 10798 & Streptococcus mitis & 49456 \\
\hline Fusobacterium nucleatum & 25586 & Streptococcus mutans & 25175 \\
\hline Fusobacterium periodonticum & 33693 & Streptococcus oralis & 35037 \\
\hline Klebsiella pneumoniae & 700721 & Streptococcus parasanguinis & 15911 \\
\hline Lactobacillus casei & 393 & Streptococcus salivarius & 25975 \\
\hline Mycoplasma salivarium & 23064 & Streptococcus sanguinis & 10556 \\
\hline Neisseria mucosa & 25996 & Streptococcus sobrinus & 27352 \\
\hline Parvimonas micra & 33270 & Tannerella forsythia & 43037 \\
\hline \multirow[t]{2}{*}{ Peptostreptococcus anaerobius } & 49031 & Treponema denticola & 35405 \\
\hline & & Veillonella parvula & 10790 \\
\hline
\end{tabular}

Figure 1- Investigated microorganisms 
including pathogens associated with denture stomatitis and periodontal disease (Figure 1).

\section{Sample size and statistical analysis}

Sample size was defined according to a previous cross-over trial ${ }^{16}$. That trial used similar outcome assessment methods and found differences in a sample of 36 participants. Therefore, this study enrolled 76 participants, which would allow for possible withdrawals and losses.

The efficacy of the denture cleaning solutions in removing biofilm was analysed using a two-way ANOVA and Tukey's test $(p<0.05)$. For remission of candidiasis, data were analyzed using multinomial logistic regression. The candidiasis scores from baseline and washout periods were considered as co-variables and candidiasis after treatment was treated as a 4-points ordinal scale. The participants' satisfaction questionnaire was adjusted by logistic regressions. The correlation structure adopted for this analysis had composite symmetry. Antimicrobial effect was analyzed as presence or absence of inflammation for each solution. First, total microbial count after each treatment was calculated and significant differences between groups were compared using generalized linear models (GLM). In a second analysis, Friedman Test followed by Dunn's multiple comparisons post-test were used to compare the effect of each solution on individual target species. Differences were considered significant when $p<0.05$. All tests were performed by the SPSS 21.0 software (SPSS Inc., Chicago, IL, USA).

\section{Results}

The final sample included 24 individuals with oral candidiasis (four men, 20 women; mean age of 69 years) and 40 without oral candidiasis (14 men, 26 women; mean age of 67 years). A flowchart of the participants of the study period is shown in Figure 2. The study was submitted to the Ethics Committee in May 2012 and was carried out from July 2012 to December 2013, being uneventfully completed. The selection of participants took place between July and August 2012.

No significant differences were observed in the ability of solutions to remove biofilm between participants with and without inflammation $(p=0.19)$ or interaction between inflammation and solution $(p=0.85)$. The remotion of biofilm was significantly influenced by the solutions $(p=0.0001)$. S1 and S2 solutions yield the lowest percentage of biofilm, followed by S3. S4 had the highest values (Figure 3).

Table 1 shows the frequency (\%) of inflammation

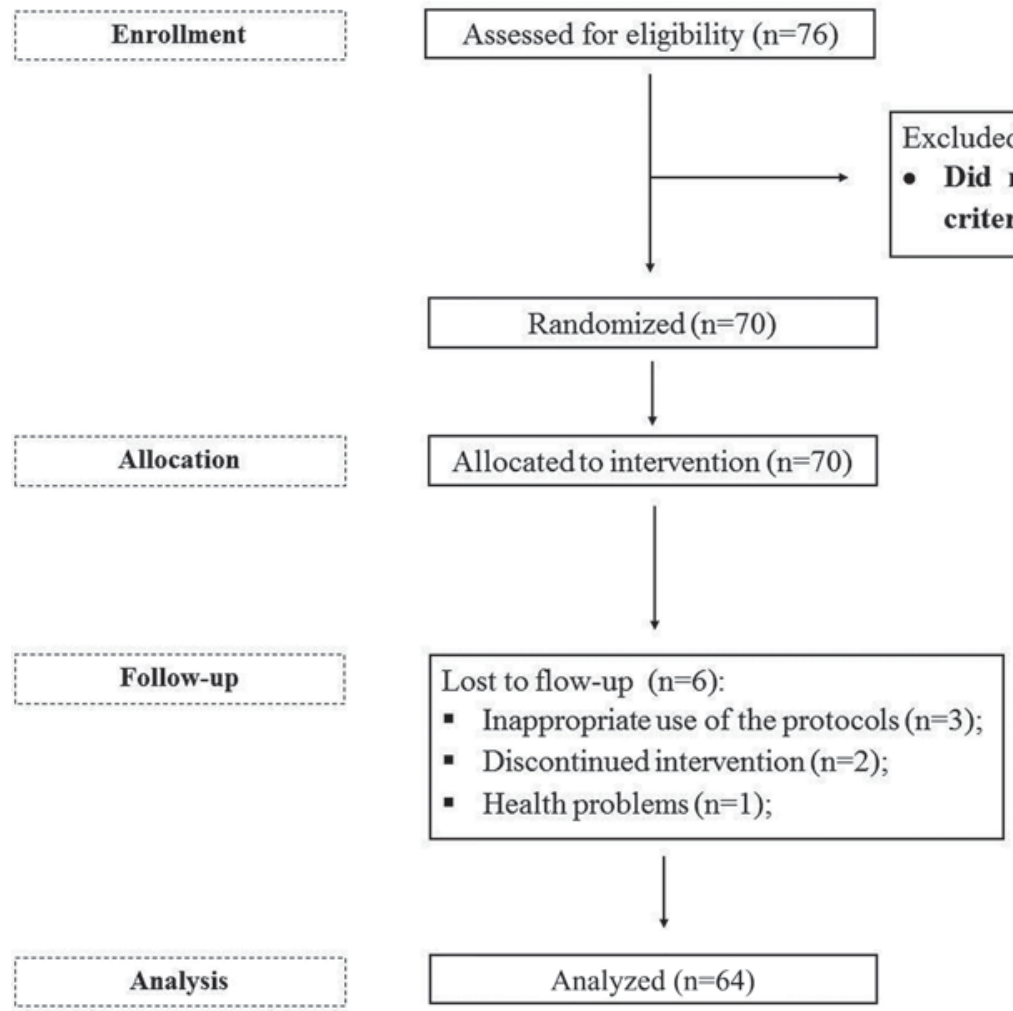

Figure 2- Flowchart of the participants of the study period 
scores at baseline, washout, and after treatments. A change from score " 1 " (satisfactory) to " 0 " (absence) and from score " 3 " (unsatisfactory) to " 2 " (regular) was found. Table 2 shows the score movement for each solution. S3 and S1 had the highest percentages of the "improved" and "cured", being equal to $50 \%$ and $46 \%$, respectively.
Multinomial logistic regression shows that a significant effect on the remission of candidiasis was observed with S3 and S1. The order and sequence of treatments had no influence in the results (Table 3 ).

Patients' satisfaction results are show in Table 4. In question 1 , the effects of different solutions $(p=0.20)$ and inflammation level $(p=0.57)$ did not

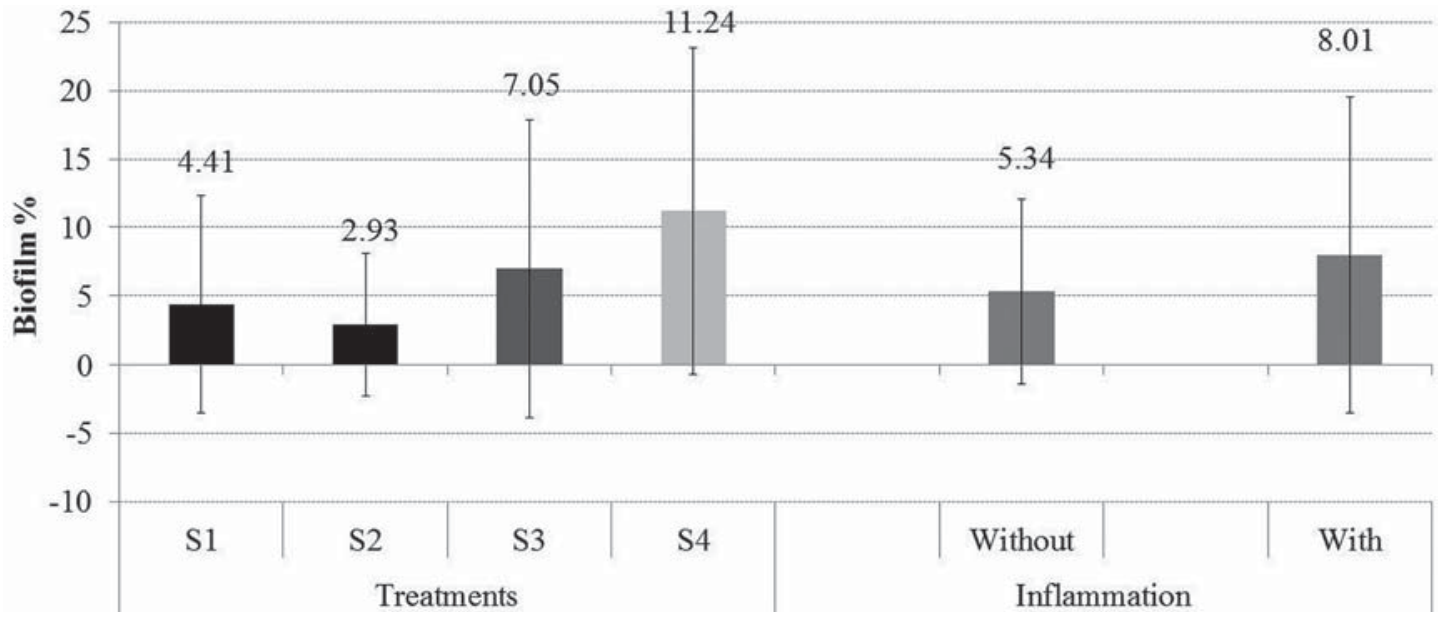

Figure 3- Mean biofilm percentage $( \pm S D)$ according to the treatments $(p=0.0001)$ and the inflammation $(p=0.19)$. Different colors indicate significant difference

Table 1- Frequency of inflammation score (F) and percentage (\%) at baseline/washout and after treatment

\begin{tabular}{|c|c|c|c|c|c|c|c|c|c|c|c|}
\hline \multirow[t]{2}{*}{ Solution } & & \multicolumn{4}{|c|}{ Baseline and Washout } & \multicolumn{6}{|c|}{ After treatment } \\
\hline & & 0 & 1 & 2 & 3 & Total & 0 & 1 & 2 & 3 & Total \\
\hline \multirow[t]{2}{*}{ S1 } & $\mathrm{F}$ & 1 & 7 & 12 & 4 & 24 & 6 & 9 & 9 & 0 & 24 \\
\hline & $\%$ & 4.2 & 29.2 & 50.0 & 16.7 & 100 & 25.0 & 37.5 & 37.5 & 0.0 & 100 \\
\hline \multirow[t]{2}{*}{ S2 } & $\mathrm{F}$ & 3 & 6 & 11 & 4 & 24 & 6 & 7 & 8 & 3 & 24 \\
\hline & $\%$ & 12.5 & 25.0 & 45.8 & 16.7 & 100 & 25.0 & 29.2 & 33.3 & 12.5 & 100 \\
\hline \multirow[t]{2}{*}{ S3 } & $\mathrm{F}$ & 3 & 8 & 8 & 5 & 24 & 6 & 10 & 7 & 1 & 24 \\
\hline & $\%$ & 12.5 & 33.3 & 33.3 & 20.8 & 100 & 25.0 & 41.7 & 29.2 & 4.2 & 100 \\
\hline \multirow[t]{2}{*}{ S4 } & $F$ & 1 & 9 & 11 & 3 & 24 & 0 & 9 & 11 & 4 & 24 \\
\hline & $\%$ & 4.2 & 37.5 & 45.8 & 12.5 & 100 & 0.0 & 37.5 & 45.8 & 16.7 & 100 \\
\hline \multirow[t]{2}{*}{ Total } & $\mathrm{F}$ & 8 & 30 & 42 & 16 & 96 & 18 & 35 & 35 & 8 & 96 \\
\hline & $\%$ & 8.3 & 31.3 & 43.8 & 16.7 & 100.0 & 18.8 & 36.5 & 36.5 & 8.3 & 100.0 \\
\hline
\end{tabular}

Table 2- Inflammation rates after treatments

\begin{tabular}{|c|c|c|c|c|c|}
\hline & Worse & Maintained & Improved & Cured & Total \\
\hline $\mathrm{S} 1$ & 0 & 13 & 6 & 5 & 24 \\
\hline$\%$ & $0.0 \%$ & $54.2 \%$ & $25.0 \%$ & $20.8 \%$ & $100 \%$ \\
\hline S2 & 2 & 15 & 3 & 4 & 24 \\
\hline$\%$ & $8.3 \%$ & $62.5 \%$ & $12.5 \%$ & $16.7 \%$ & $100 \%$ \\
\hline S3 & 1 & 11 & 9 & 3 & 24 \\
\hline$\%$ & $4.2 \%$ & $45.8 \%$ & $37.5 \%$ & $12.5 \%$ & $100 \%$ \\
\hline S4 & 6 & 13 & 5 & 0 & 24 \\
\hline$\%$ & $25.0 \%$ & $54.2 \%$ & $20.8 \%$ & $0.0 \%$ & $100 \%$ \\
\hline Total & 9 & 52 & 23 & 12 & 96 \\
\hline$\%$ & $9.4 \%$ & $54.2 \%$ & $24.0 \%$ & $12.5 \%$ & $100 \%$ \\
\hline
\end{tabular}


influence patient's responses, and the inflammation $x$ solution interaction could not be assessed due to lack of variability of the responses. Regarding questions 2 (solution: $p=0.9$; inflammation: $p=0.8$; interaction: $\mathrm{p}=0.9$ ), 3 (solutions: $\mathrm{p}=0.2$; inflammation: $\mathrm{p}=0.2$; interaction: $p=0.5$ ), 5 (solutions: $p=0.7$; inflammation: $p=0.8$; interaction: $p=0.08$ ), and 6 (solutions: $p=0.6$; inflammation: $p=0.5$; interaction: $p=0.2$ ), results were also non-significant. Regarding question 4, only the effect of inflammation could be assessed, which was also non-significant $(p=0.6)$.

For DNA-Checkerboard hybridization results, no differences were found in the amount of total microorganism count between groups with and without candidiasis ( $p=0.75$; Figure 4 ) or in the interaction between inflammation and solution $(p=0.98)$. Total microorganisms counts were similar after use of $\mathrm{S} 1$, S2, and S3 solutions and lower than S4 (Figure 5).

Table 3- Effect of source factors on remission of candidiasis

\begin{tabular}{ccccc}
\hline & Num DF & Den DF & F Value & Pr $>$ F \\
\hline Baseline and washout & 3 & 61 & 4.51 & 0.0064 \\
Treatment & 3 & 61 & 4.44 & 0.0069 \\
Order & 3 & 61 & 0.52 & 0.74 \\
Sequence & 3 & 20 & 0.5412 \\
\hline
\end{tabular}

Num DF and Den DF: Degrees of freedom used in determining the F values.

$\operatorname{Pr}>\mathrm{F}$ : $\mathrm{p}$-value associated with the $\mathrm{F}$ value of the statistical test. The null hypothesis the specified canonical correlations are equal to zero is evaluated with regard to this $p$-value. The null hypothesis is rejected if the $p$-value is less than the specified alpha level (0.05).

$\mathrm{F}$ Value - $\mathrm{F}$ Value - Test the hypothesis that both canonical correlations are equal to zero in the sample.

Table 4- Percentage of patients for score 0 or 10 for each question and treatment

\begin{tabular}{|c|c|c|c|c|c|}
\hline & Score & S1 & S2 & S3 & S4 \\
\hline \multirow[t]{2}{*}{ Q1 } & 0 & $1.6 \%$ & $1.6 \%$ & $6.2 \%$ & $6.2 \%$ \\
\hline & 10 & $98.4 \%$ & $98.4 \%$ & $93.8 \%$ & $93.8 \%$ \\
\hline \multirow[t]{2}{*}{ Q2 } & 0 & $15.6 \%$ & $20.3 \%$ & $10.9 \%$ & $7.8 \%$ \\
\hline & 10 & $84.3 \%$ & $79.7 \%$ & $89.1 \%$ & $92.2 \%$ \\
\hline \multirow[t]{2}{*}{ Q3 } & 0 & $31.3 \%$ & $20.3 \%$ & $17.2 \%$ & $18.8 \%$ \\
\hline & 10 & $68.8 \%$ & $79.7 \%$ & $82.8 \%$ & $81.3 \%$ \\
\hline \multirow[t]{2}{*}{ Q4 } & 0 & $4.7 \%$ & $0 \%$ & $1.6 \%$ & $0 \%$ \\
\hline & 10 & $95.3 \%$ & $100 \%$ & $98.4 \%$ & $100 \%$ \\
\hline \multirow[t]{2}{*}{ Q5 } & 0 & $9.4 \%$ & $6.3 \%$ & $9.4 \%$ & $6.3 \%$ \\
\hline & 10 & $90.6 \%$ & $93.8 \%$ & $90.6 \%$ & $93.8 \%$ \\
\hline \multirow[t]{2}{*}{ Q6 } & 0 & $6.3 \%$ & $6.3 \%$ & $9.4 \%$ & $6.3 \%$ \\
\hline & 10 & $93.8 \%$ & $93.8 \%$ & $90.6 \%$ & $93.8 \%$ \\
\hline
\end{tabular}

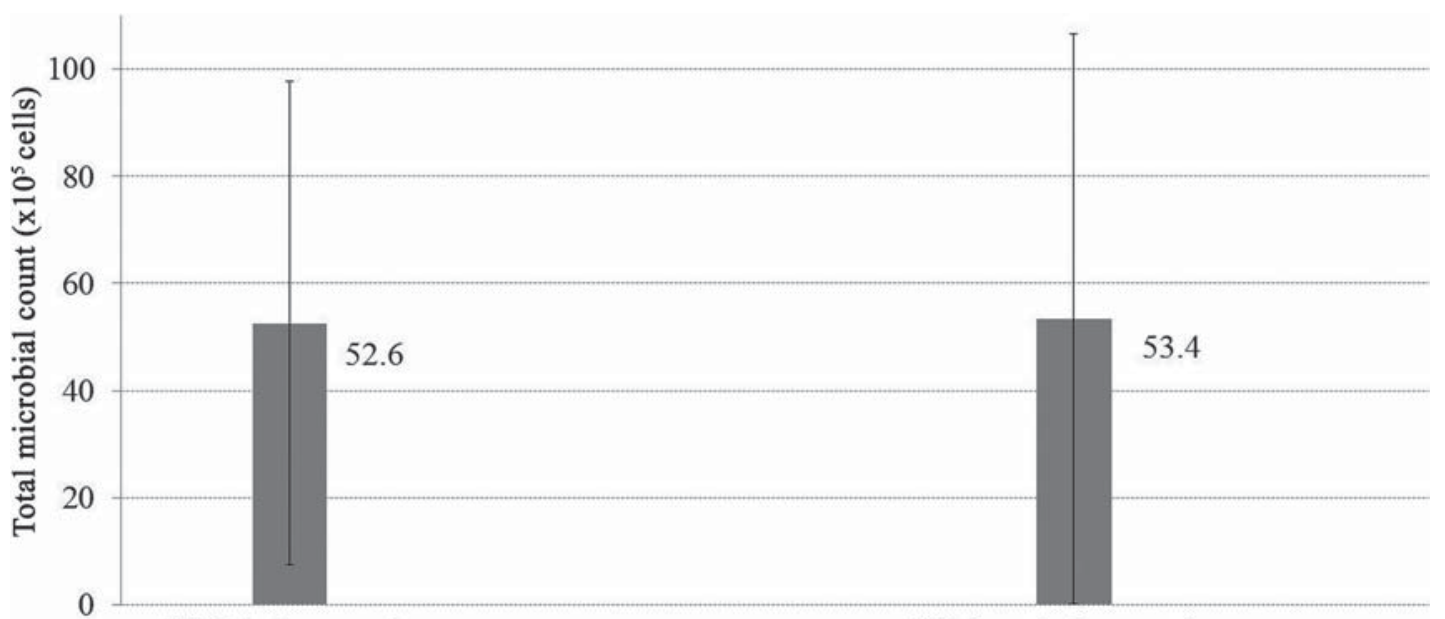

With inflammation

Without inflammation

Figure 4- Mean total microbial count $\left(\times 10^{5}\right.$ cells, $\left.\pm S D\right)$ of the groups with and without inflammation $(p=0.075)$ 


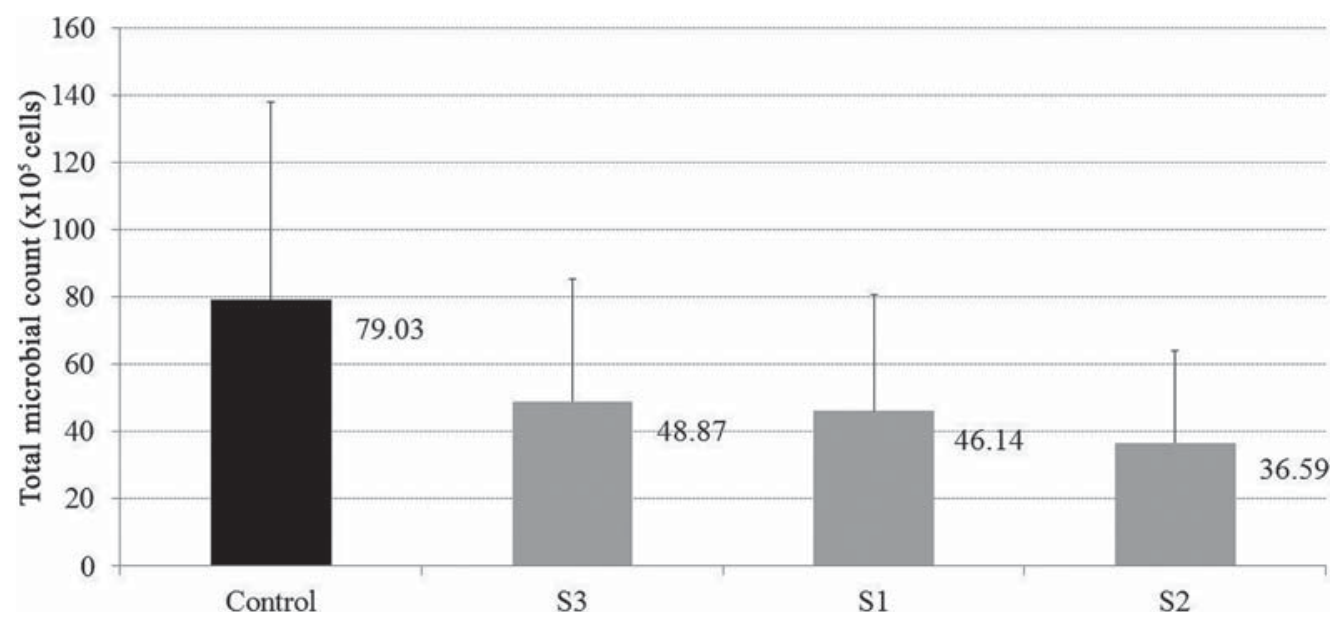

Figure 5- Mean total microbial count $\left(\times 10^{5}\right.$ cells, $\left.\pm S D\right)$ of the 43 evaluated species dentures after treatment (Different colors indicate significant differences; $\mathrm{P}=0.041$ )

The effects of solutions on individual microorganism count are shown in Table 5. S1 and S3 showed intermediate efficacy between S2 and S4 against fifteen microorganisms (C. tropicalis; C. krusei; S. sanguinis; S. oralis; S. mutans; P. intermedia; L. casei; C. rectus; A. actinomycetemcomitans serotype b; S. moorei; S. constellatus; P. putida; P. micra; P. anaerobios; K. penumoniae). S2 and S3 were efficient against $\mathrm{C}$. dubliniensis and $\mathrm{P}$. melaninogenica. S1 and S2 caused significant reductions for F. nucleatum, S. pasteuri, P. endodontalis, N. mucosa, and F. periodonticum. $\mathrm{S} 3$ was effective against $\mathrm{P}$. aeruginosa. $\mathrm{S} 1$ and $\mathrm{S} 3$ caused a mild reduction in the count of $\mathrm{E}$. coli and A. actinomycetemcomitans serotype a, against which S1 was more efficient.

\section{Discussion}

The association of mechanical and chemical methods have been recommended for the control of denture biofilm formation, thus avoiding the development of inflammatory processes ${ }^{7,14,16,22}$. The most commonly used chemical solution is $\mathrm{NaClO}$, however it can cause deleterious effects to the denture when used at $1 \%$ or $0.5 \%$ concentrations $4,17,19,20$. Therefore, the assessment of $\mathrm{NaClO}$ at lower concentrations, as well as of new chemicals, is needed to help clinicians and patients find more suitable solutions.

The first null hypothesis was partially accepted. S1 was similar to $\mathrm{S} 2$ in the ability to remove biofilm, followed by S3. Results showed that S1, S2, and S3 solutions significantly reduced total (pool) and individual microbial counts of target species. All treatments were better than control (S4). Previous studies have shown that the immersion of dentures in $0.5 \%$ sodium hypochlorite is effective in biofilm removal $^{2}$ and in the reduction of microorganism count $^{22,23}$. These results demonstrate that lower concentrations of sodium hypochlorite or the use of R. communis are an effective solution against biofilm formation and for microorganism reduction and an alternative for hypochlorite at $0.5 \%$, which have been recommended from other studies $8,22,23$. Percentages of biofilm and the microorganism count were not influenced by the presence or absence of inflammation. However, it is still necessary to evaluate the adverse effects of $0.25 \% \mathrm{NaClO}$ and $10 \% \mathrm{R}$. communis (S3) on the acrylic resin of the denture. In the literature, only one study evaluated the surface roughness with the same solutions, which demonstrated clinically acceptable values, once they were below of $0.2 \mu \mathrm{m}^{4}$.

R. communis was used in this investigation once it shows antimicrobial properties similar to $\mathrm{NaClO}$ when used in root canals with necrotic lesions ${ }^{11}$. In addition, it is also biocompatible ${ }^{9}$ and has detergent properties. There are studies evaluating the efficiency of R. communis solution in achieving complete denture hygiene, although experimental designs are diverse and results are inconclusive 2,10,19,20,22,23.

$\mathrm{S} 3$ solution showed mild results in biofilm removal. Andrade, et al. ${ }^{2}$ (2014) reported similar ratios between $2 \%$ R. communis and alkaline peroxide, but different ratios from $1 \% \mathrm{NaClO}$. Based on those previous findings, this study evaluated a higher R. communis concentration $(10 \%)$, as an attempt to reach similarity with $\mathrm{NaClO}$. Although biofilm reduction with $\mathrm{S} 3$ was lower than with hypochlorite, S3 presented better results than the control. Thus, $R$. communis can be considered an alternative to hypochlorite for allergic 
竞 罱

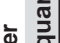

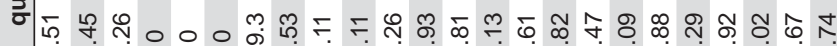

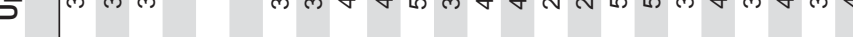
承 旁 ठँ कि ๘

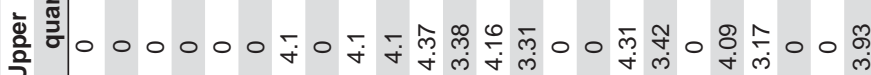

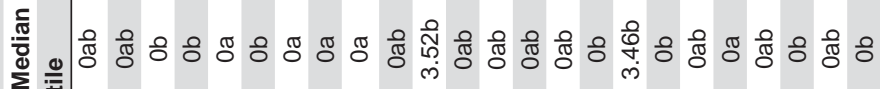
๓๐亠े

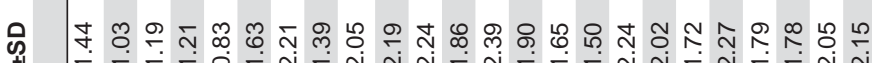
드

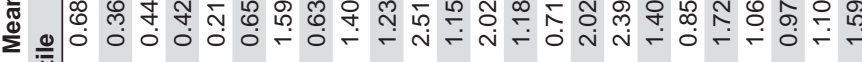

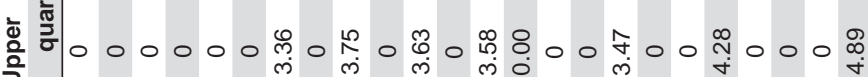
䍃 के วั้ ֻุ๊

के

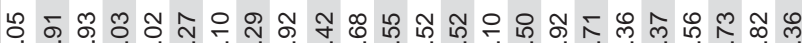

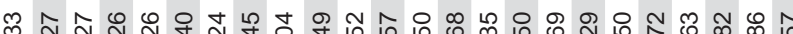

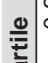

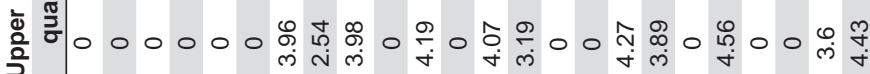

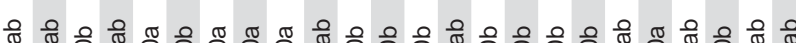
竞

000000000000000000000000

कि

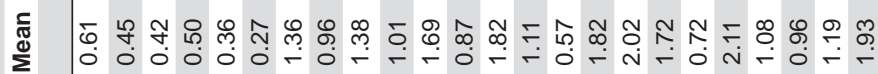

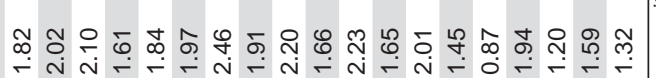

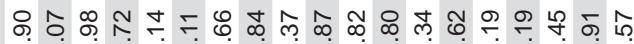

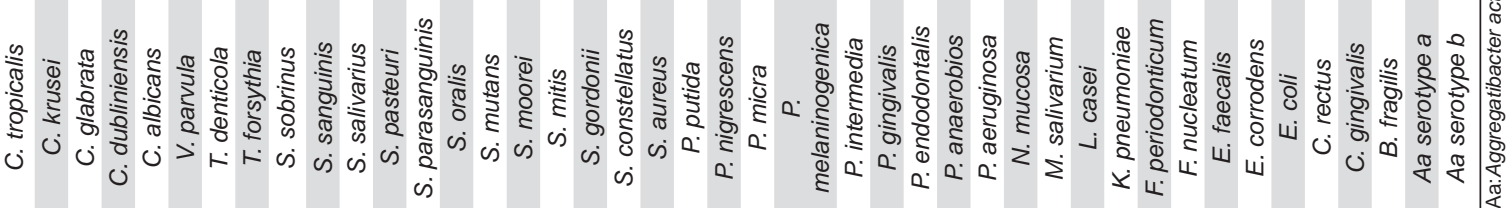

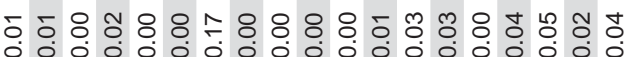

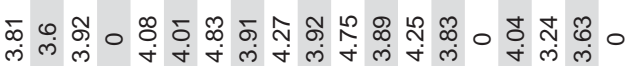

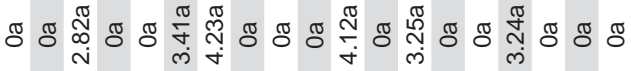
0000000000000000000

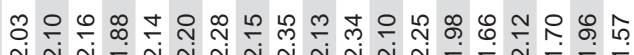
\&

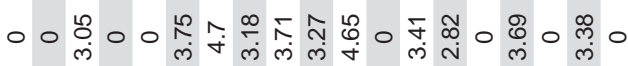

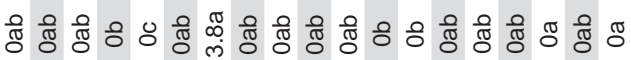
0000000000000000000

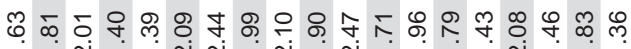

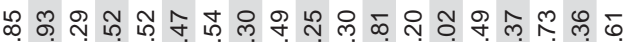

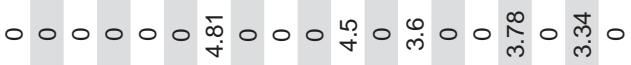

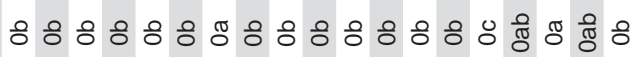
0000000000000000000

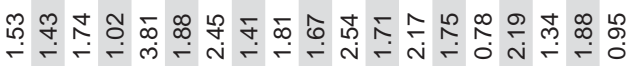

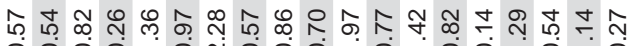

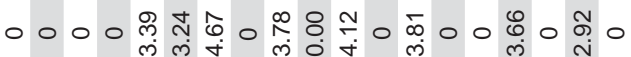

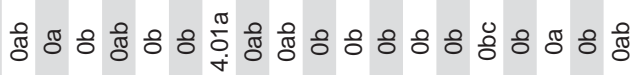
0000000000000000000

$$
\text { (1) }
$$


patients, once it also presents biocompatibility with living tissues ${ }^{6,9}$.

When the effects of the solutions on individual microorganisms were evaluated, S3 showed similar results to hypochlorite (S1 and S2) against C. glabrata, V. parvula, S. salivarius, S. mitis, S. gordonii, S. moorei, P. nigrescens, E. faecalis, and E. corrodens. S3 had also the same effect as $\mathrm{S} 2$ against $\mathrm{P}$. anaerobius and C. dublinienses; S3 was more effective than $\mathrm{S} 1$ and $\mathrm{S} 2$ against $\mathrm{P}$. aeruginosa. Against other microorganisms such as C. tropicalis, C. krusei, E. coli, and S. mutans, S3 showed results that were mild, less effective than both concentrations of hypochlorite but more effective than saline. It is noteworthy that no difference between treatments was found in the count of C. albicans and S. aureus, two important species found in the denture biofilm. Studies have reported that the detergent properties of $\mathrm{R}$. communis cause damage to the cell wall, resulting in loss of the constituents of cytoplasm and subsequent cell death $^{12,30}$. These action mechanisms however need to be further investigated.

The use of saline as a control substance resulted in the highest percentage of biofilm among the evaluated solutions. This result was expected and confirmed the findings of Andrade, et al. ${ }^{2}$ (2014). However, the act of brushing followed by immersion in saline reduced the amount of biofilm when compared to baseline, confirming the efficiency of mechanical brushing found in previous studies ${ }^{16}$. However, while brushing efficiently cleans the denture surface from solid particles, it is not enough for eliminating microorganism from micro-irregularities of denture surfaces. Thus, the association of mechanical and chemical methods is recommended for proper denture hygiene ${ }^{7,22}$. This effective association explains the significantly reduced counts of microorganisms in dentures treated with antimicrobial solutions which, in turn, cause the dissolution of the biofilm organic matrix.

Regarding the remission of candidiasis, the immersion in $10 \%$ R. communis and $0.25 \%$ sodium hypochlorite results in lower scores of inflammation than $0.5 \%$ sodium hypochlorite. S3 solution had the best results for remission of candidiasis in $50 \%$ of participants. This finding corroborates Pinelli, et al. ${ }^{18}$ (2013), in whose study a castor oil based solution improved clinical symptoms of candidiasis in older adult patients, similarly to the effect of Miconazole. In this study, $\mathrm{NaClO}$ solution was more efficient at $0.25 \%$ than at $0.5 \%$ concentration. This result is contrary to most studies on the $\mathrm{NaClO}$ ability of biofilm removal and antimicrobial action. Perhaps an allergic and/ or irritant action caused by residual waste solutions employed in acrylic resin, could influence the degree of inflammation seen on the oral mucosa of the palate and/or alveolar ridge ${ }^{3}$. A limitation of this study was that residual effect of $\mathrm{NaClO}$ on the acrylic resin was not evaluated. Moreover, clinical trials evaluating the irritating action of hypochlorite on the oral mucosa and long-term evaluation are necessary.

Patients with and without denture stomatitis participated in this study in order to determine whether the analyzed solutions can be used for cleaning of dentures giving preventive and curative actions against candidiasis.

Results of the questionnaire showed that $\mathrm{S} 1$, S2, and S3 had similar patient approval than saline, rejecting the second null hypothesis. This demonstrates that the use of these solutions did not cause any inconvenience to participants, which would have a positive influence in patient compliance with prostheses home care. However, this is in contrast with some studies that emphasize malodor and unpleasant taste of $\mathrm{NaClO}$ as one of its disadvantages.

Finally, this study reinforces that $10 \% \mathrm{R}$. communis and $0.25 \% \mathrm{NaClO}$ solutions can be used as denture cleanser replacing the $0.5 \% \mathrm{NaClO}$ as auxiliary agent for the mechanical method of brushing. Other studies should be used in addition, evaluating these solutions to reinforce their viability of use such as research on biomechanical analysis.

\section{Conclusion}

Tested solutions caused significant reduction in biofilm percentage, in total microorganisms count, and were approved by the participants. R. communis solution and $0.25 \% \mathrm{NaClO}$ were effective in the remission of candidiasis. $0.25 \%$ sodium hypochlorite and $R$. communis can be indicated as a denture cleanser.

\section{Acknowledgement}

The authors would like to thank - São Paulo Research Foundation (process number: 2012/098349 and 2012/08292-8) and Professor Gilberto Chierice 
(ICQ, São Carlos, University of São Paulo).

\section{References}

1- Ambjornsen E, Rise J, Haugejorden O. A study of examiner errors associated with measurement of denture plaque. Acta Odontol Scand. $1984 ; 42(3): 183-91$.

2- Andrade IM, Andrade KM, Pisani MX, Silva-Lovato $\mathrm{CH}$, Souza RF, Paranhos HF. Trial of an experimental castor oil solution for cleaning dentures. Braz Dent J. 2014;25(1):43-7.

3- Aparecida Guimarães M, Rocchetto Coelho L, Rodrigues Souza R, Ferreira-Carvalho BT, Marie Sá Figueiredo A. Impact of biocides on biofilm formation by methicillin-resistant Staphylococcus aureus (ST239-SCCmecIII) isolates. Microbiol Immunol. 2012;56(3):203-7. 4- Badaró MM, Salles MM, Arruda CN, Oliveira VC, Souza RF, Paranhos $\mathrm{HF}$, et al. In vitro analysis of surface roughness of acrylic resin exposed to the combined hygiene method of brushing and immersion in Ricinus communis and sodium hypochlorite. J Prosthodont. In press 2016. doi: 10.1111/jopr.12436.

5- Bloem TJ, Razzoog ME. An index for assessment of oral health in the edentulous population. Spec Care Dentist. 1982;2(3):121-4.

6- Carvalho TL, Araújo CA, Teófilo JM, Brentegani LG. Histologic and histometric evaluation of rat alveolar wound healing around polyurethane resin implants. Int J Oral Maxillofac Surg. 1997;26(2):149-52.

7- Cruz PC, Andrade IM, Peracini A, Souza-Gugelmin MC, Silva-Lovato $\mathrm{CH}$, Souza RF, et al. The effectiveness of chemical denture cleansers and ultrasonic device in biofilm removal from complete dentures. J Appl Oral Sci. 2011;19(6):668-73.

8- Freitas Fernandes FS, Pereira-Cenci T, Silva WJ, Ricomini AP Filho, Straioto FG, Del Bel Cury AA. Efficacy of denture cleansers on Candida spp. Biofilm formed on polyamide and polymethyl methacrylate resins. J Prosthet Dent. 2011;105(1):51-8.

9- Huo L, Wang D, Liu H, Jia P, Gao J. Cytoxicity, dynamic and thermal properties of bio-based rosin-epoxy resin/ castor oil polyurethane/ carbon nanotubes bio-nanocomposites. J Biomater Sci Polym Ed. 2016;27(11):1100-14

10- Leite VM, Pinheiro JB, Pisani MX, Watanabe E, Souza RF, Paranhos $\mathrm{HF}$, et al. In vitro antimicrobial activity of an experimental dentifrice based on Ricinus communis. Braz Dent J. 2014;25(3):191-6.

11- Meneghin MP, Nomelini SM, Sousa-Neto MD, Marchesan MA, Franca SC, Santos HS. Morphologic and morphometric analysis of the root canal apical third cleaning after biomechanical preparation using 3.3\% Ricinus communis detergent and $1 \% \mathrm{NaOCl}$ as irrigating solutions. J Appl Oral Sci. 2006;14(3):178-82.

12- Messetti MA, Santos AM, Angelis DF, Chierice GO, Claro Neto S. Estudo do derivado do óleo de Ricinus communis L. (mamona) como agente biocida e redutor da viscosidade produzida por Leuconostoc mesenteroides em indústrias sucroalcooleiras. Arq Inst Biol. 2010;77(2):301-8.

13- Nascimento C, Albuquerque RF Jr, Monesi N, Candido-Silva JA. Alternative method for direct DNA probe labeling and detection using the checkerboard hybridization format. J Clin Microbiol. 2010;48(8):3039-40.

14- Nishi Y, Seto K, Kamashita Y, Kaji A, Kurono A, Nagaoka E. Survival of microorganisms on complete dentures following ultrasonic cleaning combined with immersion in peroxide-based cleanser solution. Gerodontology. 2014;31(3):202-9.
15- Panariello $\mathrm{BH}$, Izumida $\mathrm{FE}$, Moffa EB, Pavarina AC, Jorge $\mathrm{JH}$, Giampaolo ET. Effect of mechanical toothbrushing combined with different denture cleansers in reducing the viability of a multispecies biofilm on acrylic resins. Am J Dent. 2016;29(3):154-60.

16- Paranhos HF, Peracini A, Pisani MX, Oliveira VC, Souza RF, SilvaLovato $\mathrm{CH}$. Color stability, surface roughness and flexural strength of an acrylic resin submitted to simulated overnight immersion in denture cleansers. Braz Dent J. 2013;24(2):152-6.

17- Paranhos HF, Silva-Lovato $\mathrm{CH}$, Souza RF, Cruz PC, Freitas KM, Peracini A. Effects of mechanical and chemical methods on denture biofilm accumulation. J Oral Rehabil. 2007;34(8):606-12.

18- Pinelli LA, Montandon AA, Corbi SC, Moraes TA, Fais LM. Ricinus communis treatment of denture stomatitis in institutionalized elderly. J Oral Rehabil. 2013;40(5):375-80.

19- Pisani MX, Macedo AP, Paranhos HF, Silva CH. Effect of experimental Ricinus communis solution for denture cleaning on the properties of acrylic resin teeth. Braz Dent J. 2012;23(1):15-21.

20- Pisani MX, Silva CH, Paranhos HF, Souza RF, Macedo AP. Evaluation of experimental cleanser solution of Ricinus communis: effect on soft denture liner properties. Gerodontology. 2012;29(2):e179-85.

21- Przybyłowska D, Mierzwińska-Nastalska E, Rubinsztajn R, Chazan $R$, Rolski $D$, Swoboda-Kopeć $E$. Influence of denture plaque biofilm on oral mucosal membrane in patients with chronic obstructive pulmonary disease. Adv Exp Med Biol. 2015;839:25-30.

22- Salles MM, Badaró MM, Arruda CN, Leite VM, Silva CH, Watanabe $\mathrm{E}$, et al. Antibiofilm activity of complete denture cleanser solutions based on sodium hypochlorite and Ricinus communis: a randomized clinical study. J Appl Oral Sci. 2015;23(6):637-42.

23- Salles MM, Oliveira VC, Souza RF, Silva-Lovato CH, Paranhos HFO. Antimicrobial action of sodium hypochlorite and castor oil solutions for denture cleaning: in vitro evaluation. Braz Oral Res. 2015;29(1):1-6. 24- Sanita PV, Machado AL, Pavarina AC, Massucato EM, Colombo AL, Vergani CE. Microwave denture disinfection versus nystatin in treating patients with well-controlled type 2 diabetes and denture stomatitis: a randomized clinical trial. Int J Prosthodont. 2012;25(3):232-44.

25- Sanitá PV, Pavarina AC, Giampaolo ET, Silva MM, Mima EG, Ribeiro DG, et al. Candida spp. prevalence in well controlled type 2 diabetic patients with denture stomatitis. Oral Surg Oral Med Oral Pathol Oral Radiol Endod. 2011;111(6):726-33.

26- Silva $\mathrm{CH}$, Paranhos HF. Efficacy of biofilm disclosing agent and of three brushes in the control of complete denture cleansing. J Appl Oral Sci. 2006;14(6):454-9.

27- Silva-Lovato $\mathrm{CH}$, Wever B, Adriaens E, Paranhos HdeF, Watanabe E, Pisani MX, et al. Clinical and antimicrobial efficacy of NitrAdineTMbased disinfecting cleaning tablets in complete denture wearers. J Appl Oral Sci. 2010;18(6):560-5

28- Silva MM, Mima EG, Colombo AL, Sanitá PV, Jorge JH, Massucato $E M$, et al. Comparison of denture microwave disinfection and conventional antifungal therapy in the treatment of denture stomatitis: a randomized clinical study. Oral Surg Oral Med Oral Pathol Oral Radiol. 2012;114(4):469-79.

29- Souza RF, Nascimento C, Regis RR, Silva-Lovato $\mathrm{CH}$, Paranhos HFO. Effects of the domestic use of a disclosing solution on the denture biofilm: a preliminary study. J Oral Rehabil. 2009;36(7):491-7.

30- Takano EH, Busso C, Gonçalves AL, Chierice GO, GuimarãesCatazarro SA, Prado-Castro MA. Inibição do desenvolvimento de fungos fitopatogênicos por detergente derivado de óleo da mamona (Ricinus communis). Cienc Rural. 2007;37(5):1235-40. 